\title{
Ontogeny has a phylogeny: background to adjunctive behaviors in pigeons and budgerigars
}

\author{
J. Mark Cleaveland, Ralf Jäger, Patricia Rößner, Juan D. Delius* \\ Allgemeine Psychologie, Universität Konstanz, Konstanz, Germany
}

\begin{abstract}
Animals coping with operant conditioning tasks often show behaviors that are not recorded by keys, levers and similar response transducers. Nevertheless, these adjunctive behaviors should not be disposed of by classifying them as incidental. Often they are found to be at least partially influenced by the experimentally programmed contingencies, and under certain conditions they can in turn influence conditioned behaviors. Here we describe the occurrence and characteristics of two such behaviors, stimulus grasping in operantly key-pecking pigeons and intra-delay stereotypies in a delayed matching-to-sample task with budgerigars. It is argued that for a proper account of these behaviors it is necessary to refer to a behavioral systems approach that appeals to longer ranging ontogenetic and phylogenetic histories than is usually considered in the psychological literature. The gaping towards on-key stimuli by pigeons is attributed to the hypothesis that operantly conditioned key-pecks probably relate to a grasp-pecking response that is normally executed towards non-edible items covering food. The intra-delay behaviors shown by the budgerigars are assumed to have originated from stress-induced displacement responses that adventitiously came under the influence of differential reinforcement contingencies. Finally, we discuss what kinds of evidence are needed to put these hypothetical explanations on a more certain footing.
\end{abstract}

Keywords: Pigeon; Pecking; Gape; Stimuli; Reward; Operant conditioning; Adjunctive behavior; Budgerigars; Delayed matching-to-sample; Displacement activities; Stereotypies

\section{Introduction}

Behaviors observed in the behaviorist's laboratory do not always conform to standard categories of conditioning. Even the comparatively simple peck of a pigeon's at a colored disk, a behavior then followed by reinforcement, is only partially described by the terms "operant" or "respondent". The form of a pigeon's peck reflects the type of reward used (Jenkins and Moore, 1973), and moreover, pigeons spontaneously

\footnotetext{
* Corresponding author. Fax: +49-753-188-318.

E-mail address: juan.delius@uni-konstanz.de (J.D. Delius).
}

approach an illuminated key that is associated with reward (Brown and Jenkins, 1968). This suggests that the key-peck of the pigeon is a response whose emergence is due primarily to respondent processes. But of course, the frequency of this behavior, or rather the frequency of mechanical key activations that signal its occurrence, changes as a function of the schedule of reward, and this is a hallmark of operant conditioning. However, there are results that do not fit comfortably with either a respondent or operant characterization. For instance, pigeons readily learn to peck or not peck differently colored keys that are differentially followed by food reward or time-out but will not easily learn 
to peck or not peck disks in the presence of sounds of different pitch that are similarly linked with either food rewards or time-out (Delius and Emmerton, 1978).

Results such as these are usually disposed of by placing them within the catch-all category "constraints on learning". They are considered as mere biases affecting the more fundamental processes of operant and respondent conditioning. This attitude goes back to the belief that a science of behavior should be concerned primarily with the control of behavior (see also Staddon, 2001). But perhaps constraints on learning are more appropriately viewed as "constraints on data". When offering accounts of behavior processes behaviorist psychologists, especially those in the Skinnerian tradition, tend to be biased by the experimental procedures that they arrange and the response transducer outputs that they obtain. As long as adequate control over these outputs is achieved, the actual behavior shown by the subjects, more often than not, receives little if any attention.

As an example of this, consider a delayed matchingto-sample task. In such a task, a sample stimulus is presented for a period of time and then removed. After this, the animal is presented with an array of comparison choice-stimuli. Of these choice-stimuli, only one, if responded to, produces reinforcement. The specific comparison stimulus that yields reinforcement depends upon the sample stimulus previously presented. The subjects' performances in such tasks, that is, the pattern of comparison choices, are often described in terms of the stimulus class jargon customary in the operant conditioning literature (e.g. Dube et al., 1987), or in terms of information processing jargon customary in the animal cognition literature (e.g. memory codes, Roitblatt, 1980). Descriptions of the actual behavior of the organism beyond response transducer activations are rarely provided and the ecological significance of the animals' performance is virtually never considered. Such descriptions, though, would certainly be relevant if the interim behaviors interfered with or even improved the control of the cue stimuli over conditioned responses. Indeed, there is some suspicion in the literature that the superior performance exhibited by humans in operant tasks is the result of a particular class of interim behavior-naming (e.g. Horne and Lowe, 1996).
As one of us argued elsewhere, a complete account of behavior that stresses explanation over control must encompass descriptions of the behavior's phylogeny, ontogeny and physiogeny (Delius, 1985). This wider approach has been variously termed a "behavioral systems approach" or a "synthetic approach to conditioned behavior" (Timberlake and Lucas, 1989; Holland, 1984), and it modifies the constraints on the learning construct from a passive receptacle into a predictive explanatory framework.

In this paper we present two experiments that illustrate the value of adopting a behavioral systems approach. The first involves a simple operant pecking task with pigeons, while the second uses a delayed matching-to-sample task with budgerigars. In both instances we are concerned not so much with the tasks themselves, as with the patterns of behavior that the subjects produced. After describing the form of our subjects' behavior, we then speculate as to its ontogenetic and phylogenetic origins.

\section{Experiment II: pigeon gape opening}

Pigeons, like other birds, use peck-like response patterns in a number of different contexts (exploration, foraging, drinking, grooming, aggression, courtship, nesting, incubation, parenting, hatching: Delius, 1985; Haag, 1991; Hörster et al., 2002; Palya and Zacny, 1980; Siemann and Delius, 1992a; Zweers, 1982). Most of these pecks involve finely adjusted beak opening and closure motions that serve to grasp items of various sizes. The kinematics of these gape responses has attracted recurring interest ever since Wolin (1968) noticed that, when rewarded with water, operantly conditioned key-pecks were executed with a nearly closed beak and, when rewarded with food, they were executed with an open beak. Jenkins and Moore (1973) reported that the same was true for respondently conditioned key-pecks. Spetch et al. (1981) found that the gape-width would alternate between narrow and wide on a trial-by-trial basis if key-pecks were alternatingly rewarded with water or food, and argued that their pigeons had learned to anticipate the two kinds of reward (see also LaMon and Zeigler, 1988).

LaMon and Zeigler (1984) established that the gape-widths of pigeons' unconditioned pecks towards seeds were adjusted to their diameters and that also the 
gape-widths of operantly conditioned key-pecks were adjusted to the sizes of the seeds offered as reward. These key-pecks were only minimally influenced by the sizes of circle stimuli displayed on the key. Subsequent studies confirmed that the gape-widths of pecks directed at food items were invariably scaled to their size to ensure grasping (Bermejo et al., 1989) and found that also the gape-width of respondently conditioned key-pecks was controlled by the size of the grains serving as unconditioned stimuli (Allan and Zeigler, 1994; Ploog and Zeigler, 1996). Ploog (2001) has recently shown that the gape-width of respondent key-pecks is really determined by the unconditioned amount of food offered, which obviously depends not only on the size but also on the quantity of items.

In the course of operant discrimination experiments where the key-pecking of pigeons was videotaped for monitoring purposes we repeatedly gained the impression that pigeons attempted to grasp differently sized stimuli projected onto the keys with suitably adjusted gapes. This was confirmed when photographs of pecks at circles of different sizes were taken for illustrative purposes, one of which is shown in Fig. 1. The experiment we now report shows more formally that con-

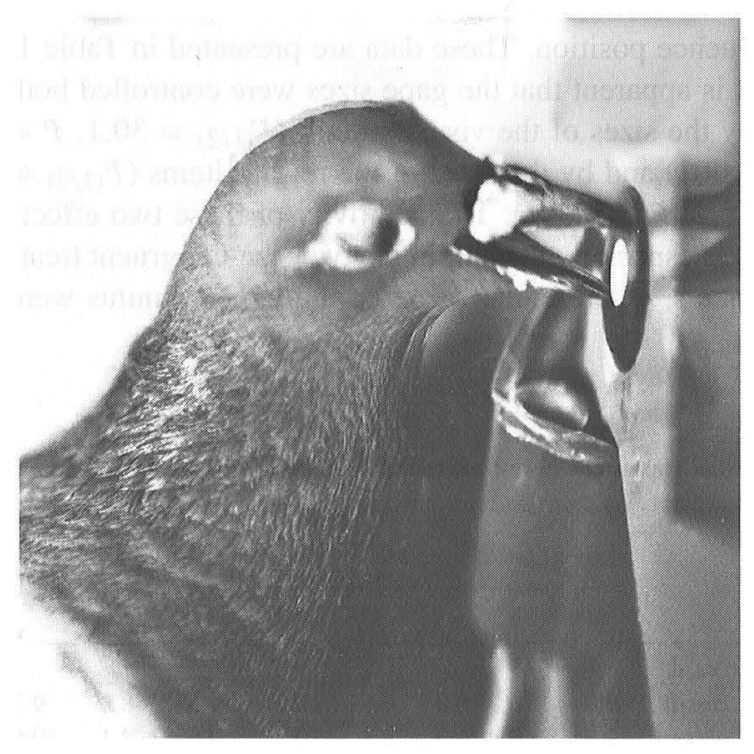

Fig. 1. Pigeon pecking at a key with a gape adjusted towards grasping a large circle. The pigeon had been instrumentally conditioned to produce key-pecks for rewards consisting of a mixture of seeds and grains. trary to LaMon and Zeigler's (1984) observations, the gape-widths of operant key-pecks are importantly determined by the size of on-key stimuli and not only by the size of the reward grains.

\subsection{Method}

\subsubsection{Subjects}

Four experimentally naive, adult domestic pigeons (Columba livia) of local homing stock were used. They were kept in individual $40 \times 45 \times 35 \mathrm{~cm}$ stainless steel grid cages located in a well ventilated and illuminated ( $12 \mathrm{~h}$ on $/ 12 \mathrm{~h}$ off) animal room and were maintained at $80 \%$ of their ad libitum weight throughout the experiment. These and all other treatments mentioned below complied with the German animal welfare laws and regulations.

\subsubsection{Apparatus}

A $35 \mathrm{~cm} \times 35 \mathrm{~cm} \times 35 \mathrm{~cm}$ conditioning chamber was used. Its left side-wall bore a $2.5 \mathrm{~cm}$ diameter translucent pecking key $22 \mathrm{~cm}$ above the floor. An opening $16 \mathrm{~cm}$ below the key allowed access to a food dispenser whenever it was raised by a solenoid. Two $2 \mathrm{~W}$ light bulbs were mounted $10 \mathrm{~cm}$ above the key. One served as a house light and the other served as a reward signal being lit whenever food was offered. With a slide projector the response key could be illuminated either fully or with a centered circular spot either 3 or $9 \mathrm{~mm}$ in diameter. The luminosity of the stimuli was adjusted to about $80 \mathrm{~cd} / \mathrm{cm}^{2}$ with a neutral density filter. The experiment was controlled by a microcomputer provided with an interface and with specially written programs (Xia et al., 1991). The transparent front wall of the chamber allowed to record the pigeons' behavior with a video camera positioned at key height. It viewed the right wall from a fixed distance and from a $35^{\circ}$ back-angle. This perspective yielded elongated, upright oval images of the pecking key. However, light reflected off the front-key surface made the back-projected stimuli invisible. Bright and even lighting was provided by three spotlights.

\subsubsection{Procedure}

The birds were first shaped to peck the key with an autoshaping procedure (Brown and Jenkins, 1968). After they had learned to key-peck in order to obtain access to mixed-sized food (see below) for periods 
of $3.5 \mathrm{~s}$ they were trained in successive sessions with increasing FR requirements until they learned to issue 20 pecks for each such reward (FR 20 schedule). Once they did so they were run for four sessions under this latter condition. Each trial began with the key being fully illuminated until the schedule requirement had been completed and the mixed-sized food reward had been issued. A 10-s interval followed during which the key was dark and inactive. The next trial began immediately afterwards. The daily sessions consisted of 30 such trials.

After this pretraining had been completed the pigeons were run in sessions in which they were presented with either the $9 \mathrm{~mm}$ or the $3 \mathrm{~mm}$ diameter sized key spot. They were rewarded with a 3-s access to $9 \pm 1.0 \mathrm{~mm}$ diameter peas or with 4 -s access to $3 \pm 0.3 \mathrm{~mm}$ diameter millet seeds, or with the already mentioned 3.5 -s access to mixed-sized food. In the latter peas were the largest items and millet seeds were the smallest items, but the mixture also contained other grains and seeds. The different access durations ensured that the three types of reward involved approximately equal volumes of food ingestion. Each of the two stimulus $\times$ three reward treatments was employed for four consecutive, daily sessions, each pigeon thus completing 24 sessions. The sequences of the treatments were randomized across the subjects. The pecking behavior was videotaped during the last two (3rd and 4th) sessions under each of the six treatments.

The gape-widths were measured in millimeters off the face of a large monitor under treatment-blind conditions. The videotapes were replayed with a 50 frames/s resolution and a single frame option was used. For a given peck the gape size was measured in the frame that depicted the actual beak-key contact, or if such a frame was not available, in the frame immediately preceding that contact. The measures were scaled relative to the $2.5 \mathrm{~mm}$ vertical key axis and recorded as distances in millimeters between the mandible tips. The back-projected stimuli, as already remarked, were not visible. Because of the fact that the tips of the mandibles were not clearly visible in all peck records and the orientation of the gapes was not always sufficiently vertically aligned and because a large number of peck records was available, a selection was both necessary and possible. Out of the 60 trials recorded under each of the stimulus/reward treatments we selected 30 trials that permitted adequate gape measurements. Out of a given trial containing 20 pecks we then measured the gapes of 3 pecks, one occurring at the beginning (1st-4th peck), one occurring in the middle (8th-11th peck) and one occurring towards the end (17th-20th peck). For gapes that were still somewhat rotated out of the vertical plane we estimated the deviation angle from the gape image (compare Fig. 1) and corrected the measure according to a geometrical nomogram. Thus, for each of the three run positions, each of the six stimulus/reward treatments and each of the four birds, 30 gapes were measured, this adding-up to a total of 2160 gape amplitude records.

\subsection{Results}

We first examined whether gape-widths within the fixed ratio peck runs might be more determined by stimulus sizes early in the run and more by the reward sizes towards the end of the run. However, regardless of the stimulus size/reward size combinations operative at the time, there was only a small increase in mean gape size across the peck runs (mean overall increase from first pecks to last pecks: $0.6 \pm 0.02 \mathrm{~mm}$, $\left.F_{(1 / 2)}=9.4 ; P<0.05\right)$.

Next we computed mean gape-widths for each bird and each stimulus/reward condition regardless of sequence position. These data are presented in Table 1 . It is apparent that the gape sizes were controlled both by the sizes of the visual stimuli $\left(F_{(1 / 2)}=30.1, P<\right.$ $0.001)$ and by the sizes of the reward items $\left(F_{(1 / 2)}=\right.$ $49.2, P<0.001)$. The additivity of these two effects was especially evident in the two size-congruent treatments, where either pecks to the large stimulus were

Table 1

Mean gape sizes in millimeter for pecks issued under six different treatments by four birds

\begin{tabular}{crrrrrrrr}
\hline & \multicolumn{1}{l}{ Stimulus } \\
\cline { 2 - 8 } & \multicolumn{1}{l}{ Small } & \multicolumn{7}{c}{ Large } \\
\hline Reward & & & & & & \\
Small & 4.9 & 5.3 & 6.3 & 6.5 & 10.2 & 9.6 & 8.2 & 9.3 \\
Mixed & 7.8 & 5.8 & 6.9 & 8.2 & 10.2 & 9.6 & 8.1 & 10.6 \\
Large & 9.1 & 6.7 & 9.4 & 9.3 & 13.0 & 12.1 & 10.7 & 12.1 \\
\hline
\end{tabular}

Each mean is based on 90 gape measurements. The S.E. of the means ranged from \pm 0.06 to $\pm 0.11 \mathrm{~mm}$, the larger errors occurring with the larger means. 


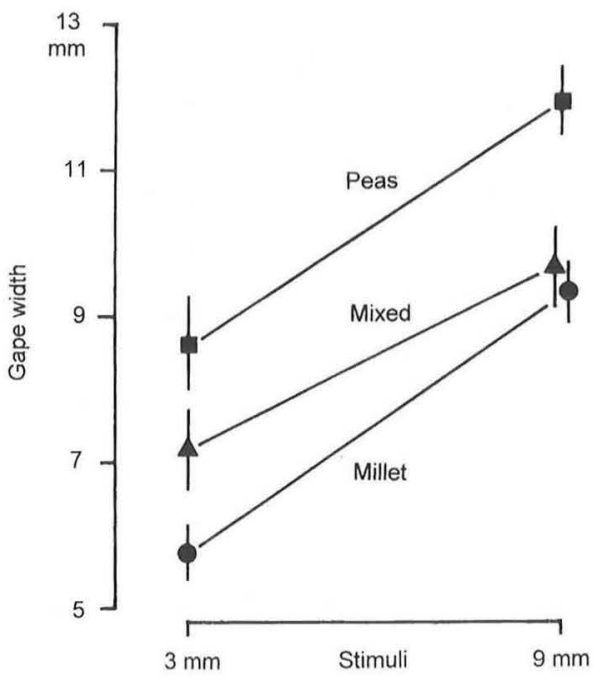

Fig. 2. Mean gape size \pm S.E. of four pigeon under six different stimulus-food treatments.

rewarded with the large peas or pecks to the small stimulus were rewarded with the small seeds. These combinations produced the largest and the smallest gapes, respectively (Fig. 2). In the two non-congruent small stimulus/large reward and large stimulus/small reward treatments the two effects nearly cancelled each other. The effect of the key stimulus sizes $S$ and the reward item sizes $R$ on the gape-width $W$ (all in millimeter) is approximately described by the function $W=0.6 S+0.4 R+3$. This is leaving aside the mixed grain treatment since there was a slight but still significant non-additive interaction between the stimulus size and reward size effects $\left(F_{(1 / 4)}=3.9\right.$, $P<0.05)$ and Fig. 2 suggested that it arose mainly through that particular treatment. The interaction may have come about through the fact that the pigeons tended to eschew the larger items of the mixture. We had, by the way, expected that the mixed reward condition would yield larger standard errors than in either the small or the large reward item treatments but this did not happen (Fig. 2). Neither could we identify any significant changes in gape-widths taking place between the $3 \mathrm{rd}$ and the 4th sessions. Such changes might have documented still ongoing readjustments to the successive stimulus size and grain size treatments. However, the design of the experiment (randomized treatment sequencing, no 1 st and 2nd session records) was poorly suited for a detection of such readjustments.

\subsection{Discussion}

The finding that the gape-width of operant keypecks in pigeons is determined both by the size of food items given as reward and by the size of on-key circle stimuli is in partial disagreement with the results reported by LaMon and Zeigler (1984). While they too found that reward item sizes strongly determined the gape-widths of operant key-pecks, the on-key stimuli they employed were found to have only a very minor effect. Differently from us, LaMon and Zeigler presented the variously sized circles in a random trial-to-trial order within a single session without any prior training, and they rewarded their birds on a FR1 schedule using same-sized peas $(7 \pm 1 \mathrm{~mm}$ in diameter) throughout. However, Jenkins and Sainsbury (1970) had earlier recorded that pigeons attempted to grasp small, distinctive features of larger on-key stimuli during an operantly conditioned discrimination task and more recently Zeigler (1997) briefly mentioned findings demonstrating that the gape-widths of respondently conditioned pecks were clearly scaled to monitor-displayed conditioned stimuli of varying sizes.

As to how the gape-width is being controlled by the size of reward items LaMon and Zeigler (1984) concluded that the visual on-key stimuli only controlled the orientation of operant pecks, whereas the adjustment of the gape-width of operant pecks were controlled by the size cues provided by preceding reward items. Upon finding that total reward volume rather than reward item size determined the gape-width of respondent pecks, Ploog (2001) argued that an associative strength mechanism, rather than a stimulus substitution process, was more likely to be at play.

As to how the gape-width might also be determined by the size of on-key stimuli there have been no suggestions. Based on experiments using rats, Holland (1984) has described several instances of respondent conditioning in which the form of conditioned responses were markedly influenced by the specifics of conditioned stimuli. When pigeons begin to respond regularly under an operant schedule they inevitably set up for themselves an effectively respondent contingency, where on-key stimuli become conditioned 
stimuli with respect to the food rewards. To the extent that conditioned stimuli can be said to partially acquire properties akin to those of unconditioned stimuli, it seems possible that on-key stimuli become food item-like and come to trigger a grasping response adjusted to their size.

However, we favor a somewhat different account. Pigeons are exceedingly adept at removing sand, grit or pebbles covering edible seeds or grains (Jäger, 1990; Siemann and Delius, 1992a). Furthermore, they can be rapidly conditioned to differentially remove particles of grit of a given color and size to uncover food items hidden beneath and to avoid pecking at grit particles of another size and color not covering such rewards (Siemann et al., 1996; Wright and Delius, 1994). Videorecordings indicate that although some of this uncovering is achieved with laterally sweeping, grit scattering pecks, a large proportion of the pecks involve a grasping and subsequent dropping of grit particles. Occasional grit particles are even swallowed; they are known to be indispensable for the grinding function of the pigeon's gizzard (Levi, 1977). The gape amplitude of the food-getting, appetitive/operant grit pecks are naturally adapted to the size of the relevant grit particles and not specially geared to the grasping of the reward items that might be eventually laid free.

We suggest that the pecking system of adult pigeons is inherently geared to adjust the gape-widths of pecks aimed at both inedible non-reward and edible reward items. If this is so, then it is logical to assume that the gape-widths observed in conditioned key-pecks, both respondent and operant, reflect this inherent arrangement.

\section{Experiment II: budgerigar delay-bridging}

This experiment examines how adjunctive behaviors might arise during and come to influence an instance of delayed matching-to-sample performance in budgerigars. As described in the Introduction, in a matching-to-sample task a sample stimulus occasions the choice of a comparison stimulus. The task is often considered purely in terms of stimulusstimulus relations. However, there is much evidence that an animal's overt behavior influences delayed matching-to-sample performance.
It has been shown that learning speed of the matching task by pigeons is determined by the number of sample stimulus pecks required (Eckerman et al., 1968). Reward schedules that produce different rates of pecking to the sample stimuli improve the acquisition of the delayed matching task and diminish the decay in performance when the delay is lengthened (Urcuioli, 1984). Differential operant responses alone can serve as sample "stimuli" (Lattal, 1975). Much evidence suggests that differential responding to the sample stimuli, and not the sample stimuli themselves, best predicts the later choice of comparison stimulus (Urcuioli, 1984, 1985; Urcuioli and DeMarse, 1994).

Regarding behavior emitted during the delay presentation Shimp and Moffit (1977) trained pigeons to peck or not peck depending on the preceding sample stimulus. Correct choice performance was maintained at long delays compared to birds that had not been trained to emit such collateral behavior. Human children have similarly been shown to benefit from trained intra-delay behaviors during delayed matching tasks (e.g. Parsons et al., 1981). Two studies (Blough, 1959; Zentall et al., 1978) have furthermore shown that pigeons occasionally will spontaneously emit untrained sample-specific stereotyped behaviors during the delay interval.

We now report results that extend Blough's and Zentall et al.'s findings to a species not often used in operant research, budgerigars. The experiment began as an attempt to differentiate among the memory codes thought to underlie delayed matching-to-sample performance. Distinct vocal responses were assigned to the stimuli used in the task. The expectation was that a so-called retrospective coding (i.e. choice controlled by sample stimuli) would be evident if the birds produced sample-related vocalizations during the delay interval. A prospective code (i.e. choice controlled by an "expectation" of the comparison stimuli) would be supported if the birds switched, at some point in the delay, to vocalizations associated with the correct comparison stimulus. However, although the birds achieved matching performances well above chance, neither result obtained. Closer observation showed that the birds engaged in various untrained intra-delay behaviors and that these response patterns correlated with the eventual comparison choice made by the subjects. 


\subsection{Method}

\subsubsection{Subjects}

Three locally bred male budgerigars (Melopsittacus undulatus) were maintained at $90 \%$ of their free-feeding weights. The birds were housed in an animal room under a 12:12-h light-dark cycle. Each bird was caged individually with free access to grit and water. All animal care followed the guidelines set out by the appropriate US animal welfare laws.

\subsubsection{Apparatus}

Birds were trained in an experimental chamber $(18 \mathrm{~cm}$ wide $\times 21 \mathrm{~cm}$ high $\times 17 \mathrm{~cm}$ deep) located in a sound-attenuating box (see Fig. 3). A grid floor $9 \mathrm{~cm}$ above the chamber base provided space for a solenoid-operated, millet seed filled food dispenser. Seven centimeters above the food dispenser, visual stimuli were presented on a small television monitor flush against a panel with three side-by-side windows $(2 \mathrm{~cm} \times 2.5 \mathrm{~cm})$. Infrared photo-electric gates detected pecks through these windows to stimuli displayed on the monitor. A perch was mounted $6 \mathrm{~cm}$ away from the display panel and just above the floor (Fig. 3). A window in the door of the sound-attenuating box provided ambient illumination from overhead room-lights.

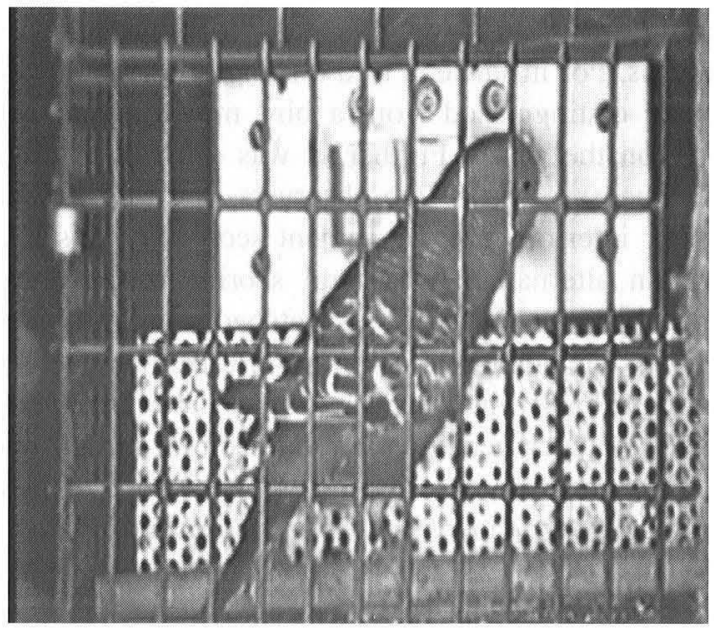

Fig. 3. Budgerigar in the experimental chamber during the delay period of a 6-s delayed matching-to-sample task. Note that the invariant features of the chamber permitted the scoring observers to overlay a locating grid as described in the text.
A microphone detected the birds' calls. Its output was fed to a digital signal processing board. The board low-pass filtered the analog data at $80 \mathrm{kHz}$ and sent it to a 16-bit analog-to-digital converter. The conversion at a sampling rate of $24 \mathrm{kHz}$ started whenever the sound intensity exceeded a pre-set value. The digital signal was then low-pass filtered at $12 \mathrm{kHz}$. Fast-Fourier transforms were performed on every $11 \mathrm{~ms}$ of digital data, and the resultant power spectra were directly accessed to the memory of a personal computer. Twenty such spectra were calculated over a 213-ms sampling period. Incoming signals were classified as calls when they lasted longer than $64 \mathrm{~ms}$ and $90 \%$ of their spectral power lay between 1 and $6 \mathrm{kHz}$. Signals recognized as calls were categorized by comparing them to each of several stored call-templates. This comparison yielded similarity indices that ranged between 0 and 1 (Manabe et al., 1997).

A camcorder, mounted on a tripod level with the stimulus display, was used to record the budgerigars' behavior through the open door of the soundattenuating box.

\subsubsection{Procedure}

The experiment involved four successive phases. Phase 1 served to isolate four quite distinct vocalizations out of each of the birds' repertoires. Phase 2 served to train each of the call responses as the conditioned response for one of four different visual stimuli. Phase 3 served to establish pecking responses towards the two visual stimuli that would serve as comparison stimuli. Phase 4 combined Phase 2-type training trials with delayed matching-to-sample trials that used two of the four visual stimuli as sample stimuli while employing the other two visual stimuli as comparison stimuli. Correct calls were demanded as sample responses while a comparison choice consisted of a single peck to the comparison stimulus.

During Phase 1 four call-templates were selected from the range of vocalizations produced by each bird on the basis of a call frequency-dependent reward schedule (cf. Manabe et al., 1997). The subjects were rewarded for producing vocalizations that differed to some degree, determined by the similarity index, from the preceding three rewarded vocalizations. This yielded clusters of calls from which four call-templates were selected. 
During Phase 2 the four templates selected for each bird were arbitrarily assigned to four discriminative stimuli: a red square, a green square, a white dot, and a white cross. During a session, a bird was randomly presented with all four stimuli each being shown 12 times behind the center window of the display. A call was deemed correct when it yielded a similarity index above 0.35 when compared with the call template assigned to the present stimulus. In addition, to be deemed correct the call had to show a similarity index below 0.35 when compared with each of the other three call-templates. A correct vocal response led to a 2-s access to food followed by a 1-s inter-trial interval. An incorrect call caused a 2 -s time-out and a repetition of the trial. Sessions lasted for 48 rewards or $20 \mathrm{~min}$, whichever occurred first. The birds were run in two or three sessions per day for 50 sessions. After this time, their vocal responses were consistently above $90 \%$ correct for each stimulus.

In Phase 3 the birds were first hand-shaped to peck the dot and a cross stimuli ( $1.5 \mathrm{~cm}$ in diameter) when they were presented singly in the side-windows. This training took approximately two sessions of $20 \mathrm{~min}$ each. Although the birds initially responded to these two stimuli with vocalizations they quickly ceased to do so and pecked at them for reward. Pecking trials were then intermixed with vocal-discrimination trials (24 of each) until the birds re-attained a better than $90 \%$ correct vocal-discrimination performance on all four stimuli.

Phase 4 involved sessions that consisted of 24 vocal-discrimination trials as before and 240 -s delayed matching-to-sample trials. Trial-types were randomly intermixed. In the matching-to-sample trials red or green presented in the center window served as sample stimuli, whereas dot and cross presented in the side windows served as comparison stimuli. The matches trained were red $\rightarrow$ dot and green $\rightarrow$ cross. A correct call extinguished the sample stimulus and immediately yielded both comparison stimuli (i.e. 0-s delay). Comparison side positions were randomly determined but balanced within a session. A peck to the correct comparison stimulus resulted in food reward followed by a 1-s inter-trial interval. An incorrect comparison choice caused a 2 -s time-out and a repetition of the trial. Sessions lasted for the sooner of 48 rewards or $20 \mathrm{~min}$. The 0 -s delay training lasted until a bird achieved three consecutive sessions of $90 \%$ or better comparison choice performance.

Upon reaching the criterion, a 0.5 -s delay was inserted between the response to the sample and the onset of the comparison. The 0.5-s delay was in effect until the bird produced more than $83 \%$ correct responses (i.e. 10 of 12 trials) to both comparison stimuli for two consecutive sessions. The delay was then gradually increased to $6 \mathrm{~s}$. Training at each successive interval duration continued until the $83 \%$ criterion was achieved or 20 sessions were completed. The computer automatically stored vocalizations produced during the delay intervals.

After reaching the criterion for the 6-s delay, each bird was videotaped during five successive sessions. The camcorder tape contents were transferred to videocassette tapes that included a timing code. These tapes were viewed at approximately one-third of normal speed. A $3 \times 4$ grid referenced to features of the chamber's interior (see Fig. 3) was laid over the video monitor. Two methods of scoring the intra-delay behaviors made by the birds were tried out. In the first instance two observers were instructed to track head positions of the budgerigars using a computer keyboard that mapped one key to each of the 12 grid-cells. Two additional keys corresponded to the start of a trial (i.e. the vocalization to the sample stimulus) and the end of a trial (a peck to one of the comparison stimuli). However, this method of scoring was found to confuse fairly obvious behavior patterns. For instance, a bird turning in a circle could not be distinguished from a bird moving back and forth on the perch. Further, it was difficult to align the time axes of the two observers, and this yielded a poor inter-observer agreement score. For this reason, an alternative behavioral scoring method was developed. An observer first watched all of the video records. He identified and characterized three well distinguishable, intra-delay behavior patterns for bird 3 and four such behavior patterns each for birds 1 and 2. This observer described these behaviors without reference to the videos or stimuli to a second observer. The two observers then independently viewed the video and noted the behavior patterns that occurred during the 1st, 4th and 6th-s periods of the available delay intervals. Using this last scoring method, the inter-observer agreement was $88 \%$ across all three birds. 

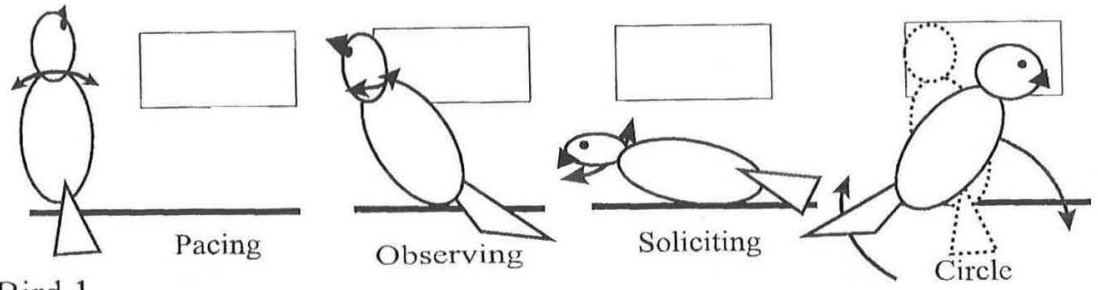

Bird 1.
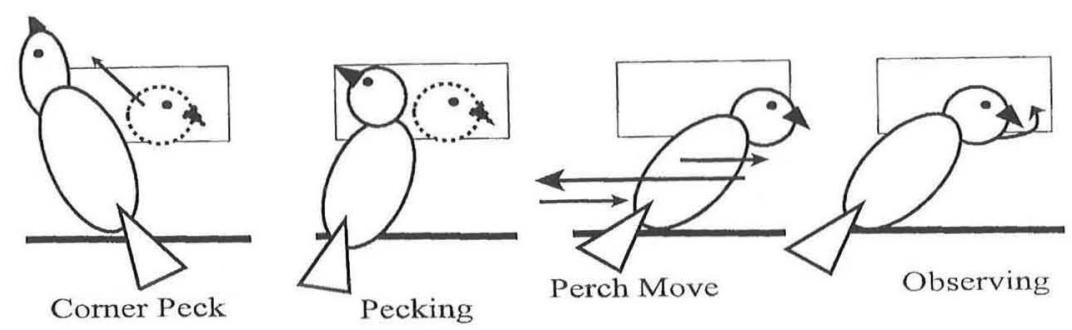

Bird 2.

Bird 3.
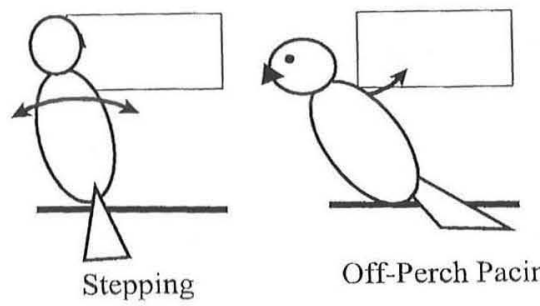

Off-Perch Pacing

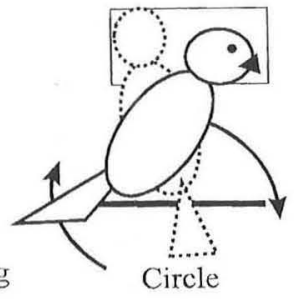

Fig. 4. Sketches of the intra-delay behavior patterns that are described in the text and which were quantitatively scored by two independent observers.

\subsection{Results}

The acquisition rate during the 0 -s delayed matching task was similar for all three budgerigars. The criterion of three consecutive days of $90 \%$ correct performance was reached in 28 sessions by bird 1,29 sessions by bird 2, and 31 sessions by bird 3 . This rate of acquisition is similar to that reported by Manabe et al. (1995) despite the fact that the present experiment involved more vocal responses and a more complex procedure. Further, at all delays greater than $0.5 \mathrm{~s}$, birds 1 and 2 achieved $83 \%$ correct performance in 20 or fewer sessions. Bird 3, on the other hand, did mot reach this criterion at delays of $2.75,3.0,3.5$ and $4.5 \mathrm{~s}$.

Vocalizations, disappointingly, were issued in less than $1 \%$ of the delay intervals across all the delay conditions. However, the birds did exhibit regular patterns of non-vocal, intra-delay behaviors during the 6-s delay interval, the only interval for which video recordings were made. These behaviors actually were only noticed by accident when video was collected to demonstrate to other researchers our experimental apparatus. Fig. 4 illustrates the specific behaviors that were identified for each subject, and Fig. 5 shows how these behaviors changed in frequency during the delay intervals of the rewarded matching-to-sample trials (that is, error trials are not represented in Fig. 5). The data were collected from the 120 rewarded matching-to-sample trials for each bird (five sessions of 24 trials per session).

Bird 1 typically began red $\rightarrow$ dot delays with a full circle turn that took the bird off the perch, to the back of the chamber and back. He then oriented himself in what we called a soliciting position until the end of the delay. This latter behavior involved a horizontal body attitude during which the bird would occasionally turn 

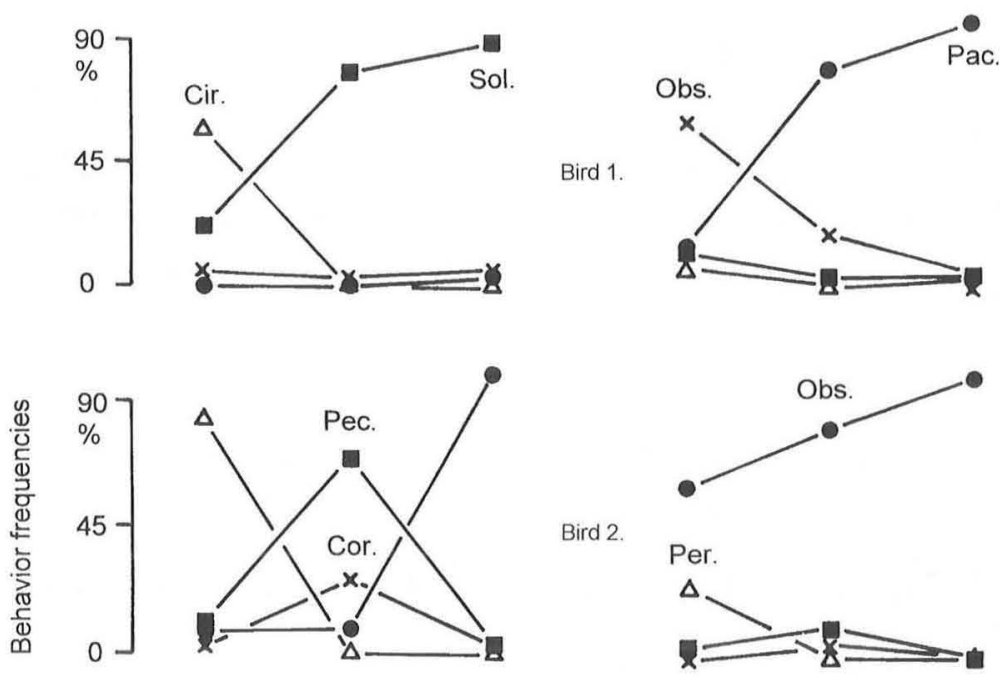

Bird 2.
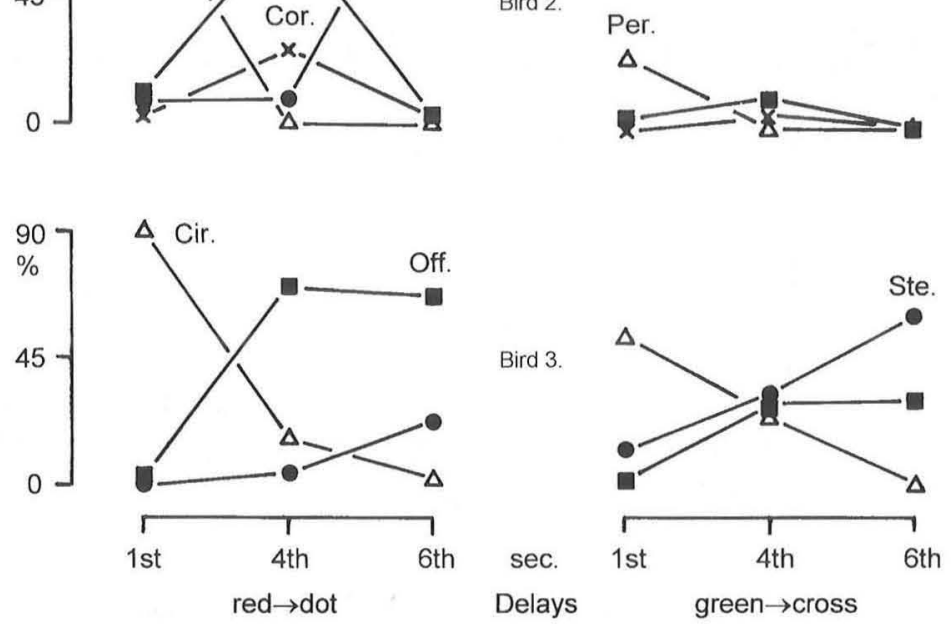

Fig. 5. Frequency in percentages of the scored intra-delay behaviors at three periods (1st, 4th and 6th-s) of the 6-s delay period. Only matching-to-sample trials ending in correct comparison choices were considered for this figure. For behavior names see Fig. 4 . Note that behaviors do not always sum to 100. This is because the behavioral categories we used did not encompass all of the behaviors emitted by the birds.

its head up toward the monitor display. The behavior also involved a slight ruffling of the feathers and minor adjustments of the feet along the perch. Green $\rightarrow$ cross delays began with the bird holding the body in a vertical position and the head tilted back. During the delay, the bird exaggerated its vertical body orientation and moved along the perch until pressed against the left wall of the chamber. During this progression the bird made rapid side-to-side movements that arose from an alternating lifting of the legs off the perch.

Bird 2 typically began red $\rightarrow$ dot delays with a lateral movement to the end of the perch to the right, to the left and then back to the central starting position. This behavior was then followed by extremely rapid pecks either to the extreme upper left corner of the experimental chamber or to a position just above the stimulus display. At the end of the delay, the bird stood directly over the food dispenser and repeatedly rotated its head in what we termed an observing response. During green $\rightarrow$ cross delays, this same bird tended to emit observing responses for the whole duration of the delay.

Bird 3 typically began red $\rightarrow$ dot delays with its head lowered close to the perch on the right side of the chamber. This position was a consequence of highly exaggerated movements made while vocalizing to the red square. The bird would then stand upright and turn in a full circle once or twice. Circling was followed 
by rapid movements off and back onto the perch on the left side of the chamber. These movements were accomplished by a single step of each foott, turning the bird to face the left wall and then the display wall. The same bird's behavioral sequence for green $\rightarrow$ cross delays began with the bird facing the display monitor with head back and beak chewing at the top of the center display window. This was followed by circling. In the middle of the green $\rightarrow$ cross delay interval, the bird was equally likely to circle, engage in offand on-perch movement as described above or engage in on-perch movement. During the latter behavior the budgerigar faced the display monitor and alternately raised each foot. This stepping was very marked, and it produced a rapid lateral weaving motion that the bird continued until the end of the delay.

Fig. 5 was exclusively created from matching-tosample trials that ended with a food reward. First, we selected the best representative behavior for each trial type (red $\rightarrow$ dot or green $\rightarrow$ cross), where best was defined as having the highest frequency-correlation with the eventual correct comparison choice. For bird 1 the behaviors considered were soliciting and pacing during the 6th-s. For bird 2 the behaviors considered were corner-pecks and observing during the 4th-s. For bird 3 the behaviors considered were off-perch pacing and on-perch stepping during 6th-s. $\chi^{2}$-tests showed that with between 58 and 60 trials available for scoring, the differential frequency of these behaviors was significant at the $P<0.001\left(\chi^{2} \geq 46.2\right.$, d.f. $\left.=1\right)$ level for each of the three budgerigars.

The frequency of these behaviors during error trials, that is, when the birds had produced the correct call in response to the sample but had then pecked the wrong comparison stimulus, was also determined. Table 2 assembles this information and shows that when a bird made such comparison choice errors, it had also tended earlier to emit an "incorrect" intra-delay behavior. For instance, when bird 1 emitted the behavior pacing at the 6th-s of the delay that began with the red stimulus, the bird tended to choose the cross comparison. However, when the same budgerigar emitted the behavior soliciting at the 6th-s of the delay that began with the red stimulus, the likelihood of an incorrect comparison choice was zero. That is, regardless of which sample stimulus began a given delay interval, bird 1 tended to make a comparison choice depending upon the behavior it happened to be emitting at the end of the delay
Table 2

Percent of occurrence of two intra-delay behaviors during 6.0-s delayed matching trials that ended with an incorrect comparison choice

\begin{tabular}{llll}
\hline \multirow{2}{*}{ Bird } & Delay behavior & \multicolumn{2}{l}{ Error trial-type } \\
\cline { 3 - 4 } & & Red $\rightarrow$ cross & Green $\rightarrow$ dot \\
\hline 1 & Pacing & 89 & 12 \\
& Soliciting & 0 & 88 \\
2 & Pecking & 56 & 25 \\
& Observing & 11 & 50 \\
3 & Off-perch & 19 & 45 \\
& Stepping & 54 & 65 \\
\hline
\end{tabular}

Note that "pacing", "pecking" and "off-perch" were typical of green $\rightarrow$ cross trials. Conversely, "soliciting," "observing" and "stepping" were typical of red $\rightarrow$ dot trials (see Fig. 5).

interval. Similar correlations between behavior-type and comparison stimulus choice are apparent in the data of all three birds. Although the number of error trials available for scoring was naturally relatively small (between 17 and 37 trials) $\chi^{2}$-tests showed that the differential frequency of the alternative behaviors shown during the two trial types was significant at the $P<0.05$ level $\left(\chi^{2} \geq 4.0\right.$, d.f. $\left.=1\right)$ for birds 1 and 3 , but not quite significant for bird 2 who had the least number of error trials. However, pooled over all three budgerigars the differential frequencies were comfortably significant $\left(P<0.01, \chi^{2}=6.8\right.$, d.f. $\left.=1\right)$.

\subsection{Discussion}

The present experiment was designed so as to test between two different memory codes thought to mediate delayed matching performance. Our hypothesis was that these codes would elicit distinctive vocalizations during the delay interval. It was predicted that a retrospective code would have yielded sample stimulus vocalizations during the delay interval. Conversely, a prospective code would have produced comparison stimulus vocalizations during the delay interval. However, it turned out that the birds only rarely vocalized during the delay interval.

Despite an absence of vocalizations during the delay periods, all of our subjects emitted stereotyped movement patterns during the 6-s delay intervals. Furthermore, these intra-delay behaviors could be classified according to the trial type, i.e. red $\rightarrow$ dot or 
green $\rightarrow$ cross (Fig. 5), and used to predict the comparison stimulus choice during error trials (Table 2). Our experiment cannot address the ontơgeny of these behavior patterns, as only the last five sessions of a single delay interval were videotaped. However, the results bear some semblance to results obtained in experiments in which the birds were found to emit seemingly irrelevant, stereotyped responses when response-contingent food is presented at fixed intervals (e.g. Falk, 1967; Staddon and Simmelhag, 1971). Falk, for example, showed rats would engage in excessive drinking, polydipsia, when food was temporally spaced and water was constantly available. Such adjunctive behaviors are characterized by the fact that they are instrumentally irrelevant in that their occurrence is not necessary to obtain reward, and yet their frequency is responsive to the schedule of rewards employed.

An account of adjunctive behaviors has been built via the assumption that regular food presentations activate a foraging-feeding system in food-deprived animals (e.g. the behavioral systems approach, Timberlake and Lucas, 1985, 1989). Such a system, it is hypothesized, is composed of species-specific behavioral patterns that reflect the acquisition and consumption of typical food items. Hence, for example, rats might engage in polydipsia because feeding and drinking became coupled as parts of an overall ingestive system during their phylogeny. However, from our own informal observations of caged budgerigar colonies and from the formal observations of others (Brockway, 1964a,b), it is doubtful that the intra-delay behaviors we observed in Experiment II involve elements of the foraging-feeding system. Adult budgerigars do engage in food sharing, in which a dominant individual regurgitates food for the benefit of a companion. This behavior, according to our own observations is often preceded by behaviors which loosely resemble the "soliciting behavior" noted here. But the frantic frequency of the other intra-delay behaviors is not obviously connected to the foraging-feeding system. Further, approaches to understanding adjunctive behaviors in general, and the behavioral systems approach specifically, do not predict the trial-specific nature of the intra-delay behaviors that we observed.

An alternative account of the intra-delay behaviors recorded might be constructed upon the fact that slight differences in movement accompanied the differen- tial calls that initiated each delay interval. One could then assume that these movement patterns were adventitiously rewarded following a correct comparison stimulus choice at the 0-s delay interval. The gradual delay increments might have then led to the shaping of two distinct intra-delay behavior patterns. Such an account has the advantage of explaining the individual differences we observed between our budgerigars. It also would explain the trial-specific nature of the intra-delay behaviors. However, this explanation is unlikely to be generally valid. Both Blough (1959) and Zentall et al. (1978) observed stereotyped intra-delay behaviors with pigeons during a delayed matching experiment despite the fact that no differential sample responding was required.

We favor a third account based upon the adventitious reward of displacement activities and stereotypic behaviors. Ethologists have long known that in stressful situations animals will often emit behavior patterns that do not appear to relate in any obvious way to the operative behavioral context (Morris, 1966; Ödberg, 1988; Tinbergen, 1952). In agonistic or unfamiliar situations birds and mammals will, for example, often engage in seemingly irrelevant grooming, foraging and sleeping activities (e.g. Delius, 1967; Feekes, 1972). To the extent that the relevant stress situation reoccurs frequently or is indeed chronic these kinds of behaviors tend to become repetitive. Chicks raised on a slatted floor, for example, are more likely to begin pecking their own or conspecific's feathers than chicks raised on a more natural litter bedding (Blockhuis and Arkes, 1984). Birds that are housed in small enclosures will engage in obsessive-like locomotor stereotypies (Keiper, 1969). Even though these behaviors appear to be functionally irrelevant they often can be influenced by external stimuli. So, for example, the degree to which a bird engages in displacement grooming or displacement feeding has been found to depend upon the kind of plumage disorder or the state of food deprivation (van Iersel and Bol, 1958; McFarland, 1965). Therefore, the intra-delay behaviors shown by the budgerigars, we suggest, are likely to be part of a more general stress response system. Which elements of this system happened to come under the control of environmental stimuli through differential reward may well have been determined in a largely accidental manner. The ecologically unusual event of having to repeatedly wait for the chance of obtaining food can 
be hypothesized to have created a stressful state (e.g. Duncan and Wood-Gush, 1972) and to have caused what has informally been called impatience stereotypies. Indeed, we predict that if budgerigars were exposed to respondent variable trace conditioning, they also would be likely to show stereotypies of this kind.

Whatever their precise genesis, the intra-delay behaviors observed raise the question of whether they themselves, rather than some hypothetical memory code, controlled the comparison choices. None of the few studies that have scored differential delay behaviors during delayed matching-to-sample tasks (Blough, 1959; Zentall et al., 1978) have managed to prove that they controlled comparison stimulus choices. To demonstrate this one would need to manipulate the intra-delay behavior patterns themselves. Blough (1959) reported anecdotal evidence to this effect in that he noticed that when he opened the experimental chamber the differential delay behaviors, and the subsequent comparison choices, were disrupted. But startling a bird in such a manner introduces many confounds, among them new visual and auditory stimuli that also could be responsible for performance disruption.

\section{General discussion}

This paper describes two findings which might be viewed as aberrant from a behavioristic perspective that assumes that behavioral control is equivalent to behavioral elucidation. In Experiment $\mathrm{I}$ it is shown that the gape-widths of operantly conditioned key-pecks of pigeons are as much determined by on-key stimulus sizes as they are by reward item sizes. This finding parallels reports that such double control occurs with respondent key-pecks but we suggest that they are the outcome of an inherent response organization. In Experiment II it was shown that untrained, intra-delay behaviors emitted by budgerigars in a delayed matching task correlated with the eventual correct or incorrect choice of comparison stimuli. This finding parallels reports of the occurrence of so-called adjunctive, feeding-like behaviors during some schedules of reward, but we suggest that the budgerigars' intra-delay responses stemmed from their stress-related repertoire.
To account for the results of Experiment I we propose that the pecking system of pigeons is normally geared to produce both appetitive and consumatory pecks serving to grasp inedible and edible items and that due to stimulus generalization the pigeons extend the beak-gaping of appetitive, food eliciting pecking to the presence of two-dimensional on-key stimuli. It is argued that appetitive grasping pecks, and hence gaping pecks are part of the normal repertoire of adult pigeons. Indeed, if offered a three-dimensional manipulandum rather than a flat surface key in either respondent or operant conditioning contexts, food rewarded pigeons tend to respond with grasp-pull rather than punch-push pecks even if the response transducer is biased to be more sensitive to impact than traction (Delius, 1992; Schall and Delius, 1991, own observations). In Experiment $I$ the gape-width of individual pecks was sometimes, particularly in the large stimulus/mixed grain and small grain conditions, too small for a potential grasping of the larger on-key stimulus. This anomaly probably arose because the two-dimensional stimuli that we used were in fact ungraspable and could thus not provide the tactile feedback that three-dimensional inedible stimuli would normally yield upon grasping.

As pointed out before the open beak pecking at keys in food rewarded conditioning contexts is not a response that comes about through a particular reinforcement contingency. This does not mean that beak-gaping, much as many other component features of pecks, can not be shaped by reward contingencies, it clearly can (Hörster et al., 2002; Jäger, 1993; Mallin and Delius, 1983; Remy and Zeigler, 1993). Nevertheless, it is patent that in the present Experiment I we undertook no such shaping of the gaping response but that this response was spontaneously and adjustedly present as part of the operantly conditioned pecking. Of course, the gape response we observed might have arisen through some suitable conditioning history during the pre-experimental life of the individual pigeons. Balsam et al. (1992) have, for example, shown that the gaping, among several other features of pecking is influenced by both respondent and operant contingencies in ring dove squabs (see also Deich and Balsam, 1994; Deich et al., 1995). Nevertheless, before any very significant learning can have occurred, barely hatched pigeon squabs exhibit 
pecking-grasping coordinations when they feed on the lumpy crop milk that is offered by the parents (Levi, 1977). Soon afterwards the squabs begin to beg for food with pecking-grasping motions directed at the parent's bill (unpublished observations). It is not unreasonable to assume that these responses arise from genetically predisposed neurodevelopmental processes and hence, must be traced back to phylogenetically assembled ontogenic programs (Dubbledam, 1998; Jäger, 1997). Here it is relevant to mention that pigeons treated with apomorphine, a potent mimic of the synaptic transmitter dopamine, produce a bout of thousands of pecks that virtually never lead to food ingestion. They are instead directed at grit particles which are grasped and dropped again or, indeed, directed at flat spots that the pigeons attempt to, but cannot grasp. These pecks do not extinguish; on the contrary, their frequency increases with repeated administrations of the drug. Their gape-width is invariably finely adjusted to the size of the inedible particles or stimuli (Keller and Delius, 2001; Siemann and Delius, 1992b; unpublished observations).

In Experiment II we again did not explicitly shape the intra-delay behaviors that we observed. We explicitly trained vocalizations, but these were not used by the birds to bridge the delay in a manner which one might hypothesize if matching-to-sample performance was controlled purely by sample and comparison stimuli. Instead, the budgerigars appeared to resort to behavior patterns whose origins remained unclear. Attention was drawn to the existence of displacement activities and stereotype behaviors, responses which ethologists have characterized as being functionally irrelevant to the contexts in which they are shown. When placed in stressful situations or environments animals are prone to engage in these seemingly superfluous, non-instrumental behaviors. Humans, for instance, will pace, scratch, smooth their hair, and bite fingernails without these behaviors having any obvious functional relation to the frustrating or thwarting situations in which they are expressed. This irrelevance does not mean that such behaviors are not under a degree of stimulus control since external circumstances can bias the frequency with which one or other response occurs. It is suggested, therefore, that the intra-delay behavior emitted by the budgerigars originated from displacement activities that came under the control of the sample stimuli and which in turn began to control the choice of comparison stimuli. Instances in which the budgerigars engaged in a false intra-delay behavior and then chose an incorrect comparison stimulus might be accounted for by a process of postural facilitation described by Lind (1959) whereby the adoption of a particular position or the execution of a particular sequence can induce the emergence of similar but alternative displacement activity through a kind of response generalization. Hull's (1934) notion of a habit family makes a similar point.

If in fact the budgerigars used their movement patterns to bridge the delay between sample and comparison stimuli, then one would predict that comparison choice performance would correlate with the degree to which these behaviors did not overlap. A bird such as subject 1 whose intra-delay behaviors were spatially distinct should show fewer errors than a bird such as subject 3 whose intra-delay behaviors showed a greater degree of spatial overlap. Future work will need to document the emergence of these spontaneous intra-delay behaviours right from the beginning of the experiment, and to determine whether these behaviors really come to control future action.

Regardless of these lacunae that remain, we hope to have intimated that it is desirable that more conditioning studies concern themselves with more than the easy to register lever presses and key-pecks and to pay increased attention to behaviors outside their experimental designs in order to contribute to the growth of a more complete, more embracing behavioral science.

\section{Acknowledgements}

The pigeon research was supported by grants from the Deutsche Forschungsgemeinschaft. R.J. is grateful to I. Krug and L. Xia for varied assistance and H.P. Zeigler and D.M. Parker for comments on an earlier draft of the pigeon experiment. The budgerigar research was supported by grants from the National Science Foundation and the National Institute of Mental Health to J.E.R. Staddon, Duke University. J.M.C. thanks K. Manabe for technical assistance and J.E.R. Staddon for comments on an earlier draft of the budgerigar experiment. 


\section{References}

Allan, R.W., Zeigler, H.P., 1994. Autoshaping the pigeon's gape response, acquisition and topography as a function of reinforcer type and magnitude. J. Exp. Anal. Behav. 62, 201-223.

Balsam, P.D., Graf, J.S., Silver, R., 1992. Operant and pavlovian contributions to the ontogeny of pecking in ring doves. Dev. Psychobiol. 25, 389-410.

Bermejo, R., Allan, R.W., Houben, D., Deich, J.D., Zeigler, H.P., 1989. Prehension in the pigeon, descriptive analysis. Exp. Brain. Res. 75, 569-576.

Blockhuis, H.J., Arkes, J.G., 1984. Some observations on the development of feather-pecking in poultry. Appl. Anim. Behav. Sci. 12, 145-157.

Blough, D.S., 1959. Delayed matching in the pigeon. J. Exp. Anal. Behav. 2, 151-160.

Brockway, B.F., 1964a. Ethological studies of the budgerigar (Melopsittacus undulatus): non-reproductive behavior. Behaviour 22, 193-222.

Brockway, B.F., 1964b. Ethological studies of the budgerigar (Melopsittacus undulatus): reproductive behavior. Behaviour 23, 294-324

Brown, P.L., Jenkins, H.M., 1968. Autoshaping of the pigeon's key-peck. J. Exp. Anal. Behav. 11, 1-8.

Deich, J.D., Balsam, P.D., 1994. Development of prehensile feeding in ring doves (Streptopelia risoria), learning under organismic and task constraints. In: Davies, M.N.O., Green, P.R. (Eds.), Perception and Motor Control in Birds. Springer, Berlin, pp. 160-181.

Deich, J.D., Tankoos, J., Balsam, P.D., 1995. Systematic changes in gaping during the ontogeny of pecking in ring doves (Streptopelia risoria). Dev. Psychobiol. 28, 147-163.

Delius, J.D., 1967. Displacement activities and arousal. Nature 214, 1259-1260.

Delius, J.D., 1985. The peck of the pigeon: free for all. In: Lowe, C.F., Richelle, M., Blackman, D.E., Bradshaw, C.M. (Eds.), Behaviour Analysis and Contemporary Psychology. Erlbaum, New York, pp. 53-81.

Delius, J.D., 1992. Categorical discrimination of objects and pictures by pigeons. Anim. Learn. Behav. 20, 301-311.

Delius, J.D., Emmerton, J., 1978. Stimulus dependent asymmetry in classical and instrumental discrimination learning by pigeons. Psychol. Rec. 28, 425-434.

Dube, W.V., McIlvane, W.J., Mackay, H.A., Stoddard, L.T., 1987. Stimulus class membership established via stimulus-reinforcer relations. J. Exp. Anal. Behav. 47, 159-175.

Dubbledam, J.L., 1998. The neural substrate for learned and non-learned activities in birds. Acta Anat. (Basel) 163, 157172.

Duncan, I.J.H., Wood-Gush, D.G.M., 1972. Thwarting of feeding behaviour in the domestic fowl. Anim. Behav. 20, 444-451.

Eckerman, D.A., Lanson, R.N., Cumming, W.W., 1968. Acquisition and maintenance of matching without a required observing response. J. Exp. Anal. Behav. 11, 435-441.

Falk, J.L., 1967. Control of schedule-induced polydipsia: type, size, and spacing of meals. J. Exp. Anal. Behav. 10, 199-206.
Feekes, F., 1972. Irrelevant ground pecking in agonistic situations in Burmese jungle fowl (Gallus gallus spadiceus). Behaviour 43, 186-236.

Haag, D., 1991. Ethogramm der Taube. Abs/Galhof, Bochum.

Holland, P.C., 1984. Origins of behavior in Pavlovian conditioning. Psychol. Learn. Motiv. 18, 129-174.

Horne, P.J., Lowe, C.F., 1996. On the origins of naming and other symbolic behavior. J. Exp. Anal. Behav. 65, 185-241.

Hörster, W., Krumm, E., Mohr, C., Delius, J.D., 2002. Conditioning the pecking motions of pigeons. Behav. Proc. 58, 27-43.

Hull, C.L., 1934. The concept of the habit-family hierarchy and maze learning: Part I. Psychol. Rev. 41, 33-54.

van Iersel, J.J.A., Bol, A., 1958. Preening of two tern species: a study on displacement activities. Behaviour 13, 1-88.

Jäger, R., 1990. Visuomotor feeding perturbations after lateral telencephalic lesions in pigeons. Behav. Brain Res. 40, 73-80.

Jäger, R., 1993. Lateral forebrain lesions affect pecking accuracy in the pigeon. Behav. Proc. 28, 181-188.

Jäger, R., 1997. Separate channels for visuomotor transformations in the pigeon. Eur. J. Morphol. 35, 277-289.

Jenkins, H.M., Moore, B.R., 1973. The form of the autoshaped response with food or water reinforcers. J. Exp. Anal. Behav. 20, 163-181.

Jenkins, H.M., Sainsbury, R.S., 1970. Discrimination learning with the distinctive feature on positive or negative trials. In: Mostofsky, D.F. (Ed.), Attention: Contemporary Theory and Analysis. Appleton Century Crofts, New York, pp. 239-273.

Keiper, R.R., 1969. Causal factors of stereotypies in caged birds. Anim. Behav. 17, 114-119.

Keller, S., Delius, J.D., 2001. Discriminative learning occasioned by the administration of a dopamine agonist. Psychopharmacology 157, 320-323.

Lattal, K.A., 1975. Reinforcement contingencies as discriminative stimuli. J. Exp. Anal. Behav. 23, 241-246.

LaMon, B.C., Zeigler, H.P., 1984. Grasping in the pigeon (Columba livia), stimulus control during conditioned and consumatory responses. Anim. Learn. Behav. 12, 223-231.

LaMon, B.C., Zeigler, H.P., 1988. Control of pecking response form in the pigeon. Anim. Learn. Behav. 16, 256-267.

Levi, W.M., 1977. The Pigeon. Levi, Sumter, NC.

Lind, H., 1959. The activation of an instinct caused by a transitional action. Behaviour 14, 123-135.

Mallin, H., Delius, J.D., 1983. Inter-and intraocular transfer of colour discriminations with mandibulation as an operant in the head-fixed pigeon. Behav. Anal. Lett. 3, 297-309.

Manabe, K., Kawashima, T., Staddon, J.E.R., 1995. Differential vocalization in budgerigars: towards an experimental analysis of naming. J. Exp. Anal. Behav. 63, 111-126.

Manabe, K., Staddon, J.E.R., Cleaveland, J.M., 1997. Control of vocal repertoire by reward in budgerigars. J. Comp. Psychol. 111, 50-62.

McFarland, D., 1965. Hunger, thirst and displacement pecking in the barbary dove. Anim. Behav. 13, 293-300.

Morris, D., 1966. Abnormal rituals in stress situations, the rigidification of behaviour. Philos. Trans. R. Soc. Lond. B251, 327-330. 
Ödberg, F., 1988. Behavioral coping in chronic stress conditions. In: Blanchard, R.J., Brain, P.F., Blanchard, D.C., Parmigiani, S. (Eds.), Ethoexperimental Approaches to the Study of Behavior. Kluwer Academic Publishers, Dordrecht, pp. 229-238.

Palya, W.L., Zacny, J.P., 1980. Stereotyped adjunctive pecking by caged pigeons. Anim. Learn. Behav. 8, 293-303.

Parsons, J.A., Taylor, D.C., Joyce, T.M., 1981. Precurrent self-prompting operants in children: "remembering". J. Exp. Anal. Behav. 36, 253-266.

Ploog, B.O., 2001. Net amount of food affects autoshaped response rate, response latency, and gape amplitude in pigeons. Learn. Motiv. 32, 383-400.

Ploog, B.O., Zeigler, H.P., 1996. Effects of food-pellet size on rate, latency, and topography of autoshaped key-pecks and gapes in pigeons. J. Exp. Anal. Behav. 65, 21-35.

Remy, M., Zeigler, H.P., 1993. Classical conditioning of jaw movements in the pigeon, acquisition and response topography. Anim. Learn. Behav. 21, 131-137.

Roitblatt, H.L., 1980. Codes and coding processes in pigeon short-term memory. Anim. Learn. Behav. 8, 341-351.

Schall, U., Delius, J.D., 1991. Grasping in the pigeon, control through sound and vibration feedback mediated by the nucleus basalis. Physiol. Behav. 50, 983-998.

Shimp, C.P., Moffit, M., 1977. Short-term memory in the pigeon: delayed-pair-comparison procedures and some results. J. Exp. Anal. Behav. 28, 13-25.

Siemann, M., Delius, J.D., 1992a. Variability of forage pecking in pigeons. Ethology 92, 29-50.

Siemann, M., Delius, J.D., 1992b. Apomorphine induced behaviour in pigeons (Columba livia). In: Elsner, N., Richter, D. (Eds.), Rhythmogenese in Neuronen und Netzwerken. Thieme, Stuttgart, p. 600.

Siemann, M., Delius, J.D., Wright, A.A., 1996. Transitive responding in pigeons: influences of stimulus frequency and reinforcement history. Behav. Proc. 37, 185-195.

Spetch, M.L., Wilkie, D., Skelton, R.W., 1981. Control of pigeon's key-pecking topography by a schedule of alternating food and water reward. Anim. Learn. Behav. 9, 223-229.

Staddon, J., 2001. The New Behaviorism: Mind, Mechanism and Society. Psychology Press, Philadelphia.

Staddon, J.E.R., Simmelhag, V.L., 1971. The "superstition" experiment: a re-examination of its implications for the principles of adaptive behavior. Psychol. Rev. 78, 3-43.
Timberlake, W., Lucas, G.A., 1985. The basis of superstitious behavior, chance contingency, stimulus substitution, or appetitive behavior. J. Exp. Anal. Behav. 44, 279299.

Timberlake, W., Lucas, G. A., 1989. Behavior systems and learning, from misbehavior to general principles. In: Klein, S.B., Mowrer, R.R. (Eds.), Contemporary Learning Theories: Instrumental Conditioning and the Impact of Biological Constraints on Learning. Erlbaum, Hillsdale, NJ, pp. 237-275.

Tinbergen, N., 1952. Derived activities: their causation, biological significance, origin, and emancipation during evolution. Quart. Rev. Biol. 27, 1-32.

Urcuioli, P., 1984. Overshadowing in matching-to-sample: reduction in sample-stimulus control by differential sample behaviors. Anim. Learn. Behav. 12, 256-264.

Urcuioli, P., 1985. On the role of differential sample behaviors in matching-to-sample. J. Exp. Psychol. Anim. Behav. Proc. 11, 502-519.

Urcuioli, P., DeMarse, T., 1994. On the relationship between differential outcomes and differential sample responding in matching-to-sample. J. Exp. Psychol. Anim. Behav. Proc. 20, 249-263.

Wolin, B.R., 1968. Differences in the manner of pecking a key in pigeons reinforced with food and water. In: Catania, A.C. (Ed.), Contemporary Research in Operant Behaviour. Scott-Foresman, Glenview, 286 pp.

Wright, A.A., Delius, J.D., 1994. Scratch and match, pigeons learn matching and oddity with gravel stimuli. J. Exp. Psychol. Anim. Behav. Proc. 20, 108-112.

Xia, L., Wynne, C.D.L., von Münchow-Pohl, R., Delius, J.D., 1991. A basic dialect for the control of psychological experiments with the Commodore-64 and Dela interfacing. Res. Meth. Instr. Comp. 23, 72-76.

Zeigler, H.P., 1997. Behavioral morphology of the pigeon's peck, ingestion, prehension, and cognition. Eur. J. Morphol. 35, 255268.

Zentall, T.R., Hogan, D.E., Howard, M.M., Moore, B.S., 1978. Delayed matching in the the pigeon, effect on performance of sample-specific observing responses and differential delay behavior. Learn. Motiv. 9, 202-218.

Zweers, G.A., 1982. Pecking of the pigeon (Columba livia). Behaviour 81, 173-230. 